\title{
Preference for signaled vs unsignaled shock in pigeons with implanted electrodes*
}

\author{
PATRICK GRIFFIN, L. MICHAEL HONAKER, DANIEL E. JONES, and LEONARD T. PYNES \\ University of Alabama, University, Alabama 35486
}

\begin{abstract}
Treadle presses in two pigeons produced changeover from a program of unsignaled, unavoidable, and inescapable shock to a program in which such shock was preceded by a 5.0-sec visual and auditory preshock signal. Different houselight colors were correlated with the two programs. Both Ss, albeit marginal in one $S$, spent more session time in the signaled shock program when the above conditions prevailed than if (a) only the stimulus correlated with the signaled shock program but not the preshock signal occurred or (b) neither preshock signal nor correlated stimulus occurred.
\end{abstract}

Knapp, Kause, and Perkins (1959) reported a preference in rats for the arm of a T-maze associated with signaled, unavoidable shock when the alternate arm was associated with unsignaled, unavoidable shock. Subsequently, Lockard (1963), Perkins, Levis, and Seymann (1963) and Perkins, Seymann, Levis, and Spencer (1966) reported such a preference in the shuttlebox where shock was signaled on one side and unsignaled on the other and preference was indexed by the proportion of session time spent on the signaled shock side. More recently, Badia and Culbertson (1972) used a procedure in which a leverpress was required to change over from an unsignaled, unavoidable shock program to a signaled, unavoidable shock program. Once initiated, the signaled shock condition remained in effect for $3.0 \mathrm{~min}$ and was correlated with an exteroceptive stimulus. Congruent with prior results, a greater proportion of session time was spent in the signaled shock condition.

Badia and Culbertson (1972) argued that the preshock signal partitioned the signal shock condition into relatively long safe and relatively short unsafe periods and that such segmentation was an important determinant of preference. It was suggested further that an experiment by Dinsmoor, Flint, Smith, and Viemeister (1969), in which stimuli that differentiated no-punishment from punishment periods maintained an observing response in pigeons, added some generality to the notion. A demonstration that pigeons prefer signaled to unsignaled shock in the Badia and Culbertson (1972) procedure would strengthen this particular generalization.

These data would be of additional interest since a reliable method of shock electrode implantation that imposes minimum restraint is available for pigeons

* This article is sponsored by A. A. Baumeister, who takes full editorial responsibility for its contents. We thank Drs. Baumeister and $P$. Weisberg for their support and Charlie $A$. Smith for assistance in preparation of the manuscript. Reprints may be obtained from the first author, Department of Psychology, University of Alabama, University, Alabama 35486.
(Azrin, 1959). This consideration is important since it has been argued that signaled shock is preferred to some extent because $\mathrm{S}$ can make postural adjustments during the signal that modify shock intensity (cf. Biederman \& Furedy, 1970). The possibility of such modification seems remote with implanted electrodes. Due to these issues, pigeons were subjected to the Badia and Culbertson (1972) procedure in the present experiment.

\section{METHOD}

\section{Subjects}

Two experimentally naive male adult Silver King pigeons were maintained with free access to food, water, and grit in individual home cages.

\section{Apparatus}

The experimental chamber was $28.7 \mathrm{~cm}$ long, $35.6 \mathrm{~cm}$ wide, and $38.1 \mathrm{~cm}$ high and, except for the Masonite response panel, had a white interior. The response panel contained a $8.4 \mathrm{x}$ $7.6 \mathrm{~cm}$ Plexiglas treadle covered with hardware cloth and centered $8.9 \mathrm{~cm}$ above the floor with the $8.4-\mathrm{cm}$ edges parallel to the panel. A dead weight of $75 \mathrm{~g}$ on the treadle closed a microswitch, produced auditory feedback, and defined the response. Two 2.54-cm-diam translucent disks, each $3.3 \mathrm{~cm}$ above the floor and $7.6 \mathrm{~cm}$ on either side of the panel midline, could be illuminated from behind the panel by $7-\mathrm{W} 110-\mathrm{V}$ ac lights (treadle lights). A $8.4 \times 3.8 \mathrm{~cm}$ translucent rectangle was embedded in the center of the panel $27.9 \mathrm{~cm}$ above the floor and could be illuminated by a $7-\mathrm{W} 110-\mathrm{V}$ ac green light (signal light). A $15.2 \times 7.6 \mathrm{~cm}$ speaker was mounted directly below the signal light behind a matrix of small holes. The speaker was used to present a $1.0-\mathrm{kHz}$ sine wave tone that raised the ambient noise level in the chamber from 75.0 to $83.0 \mathrm{~dB}$ (A scale, Triplett Model 370 sound level meter). All programming and recording equipment was acoustically isolated in a separate room.

Electric shock was delivered through $10 \mathrm{~K} \mathrm{ohms} \mathrm{series}$ resistance to Nichrome implanted electrodes (Azrin, 1959). Shock level is specified in rms voltage at the source.

\section{Procedure}

Initially, each $\mathrm{S}$ was given three 3.0-h daily sessions in which the treadle lights were white (S P1) or red (S P2) throughout and $0.5-\mathrm{sec} 60-\mathrm{V}$ shock was delivered on a variable time $120-\mathrm{sec}$ schedule. Each shock was preceded by a 5.0-sec signal consisting of the $1.0-\mathrm{kHz}$ tone plus the signal light. These events coterminated with shock onset. Subsequently, the following 
experimental conditions were imposed in which the average intershock interval was $90.0 \mathrm{sec}$. The condition abbreviations correspond to those in Badia and Culbertson (1972).

Changeover to Signaled Shock (CO). Each 3.0-h session began with the unsignaled shock component (red, S P1; white, S P2) in which 0.5 -sec shocks were unsignaled. A single treadle press initiated the signaled shock component and changed the color of the treadle lights (correlated stimulus). During the signaled shock component, each shock was preceded by the 5.0 -sec compound of tone plus signal light. Each time the signaled shock component was initiated, it remained in effect for $3.0 \mathrm{~min}$ irrespective of responses during the component. However, if the 3.0 -min limit expired during a preshock signal, the component was held until after shock delivery.

Extinction 1 (EXT 1). The unsignaled shock condition remained in effect throughout the session. Thus, responses had no scheduled consequences.

Extinction 2 (EXT 2). Shocks were not signaled in either component, but responses could produce the correlated stimulus associated with signaled shock in the CO condition. During both extinction conditions, a response still initiated the recording circuitry for time in the signaled shock component.

\section{RESULTS}

Figure 1 presents the proportion of session time spent in the signaled shock component over the final six sessions of each condition. This variable name is, of course, a misnomer for the extinction conditions, since no signal (EXT 2) or neither signal nor correlated stimulus (EXT 1) occurred. The experimental conditions did not consistently affect preference in either $S$ when shock intensity was $60 \mathrm{~V}$. However, with $80 \mathrm{~V}, \mathrm{~S} \mathrm{P} 2$ spent a greater proportion of session time in the signaled shock component during $\mathrm{CO}$ than during either EXT 1 or EXT 2. Pigeon P1 evidenced qualitatively similar effects; however, there was considerable overlap in

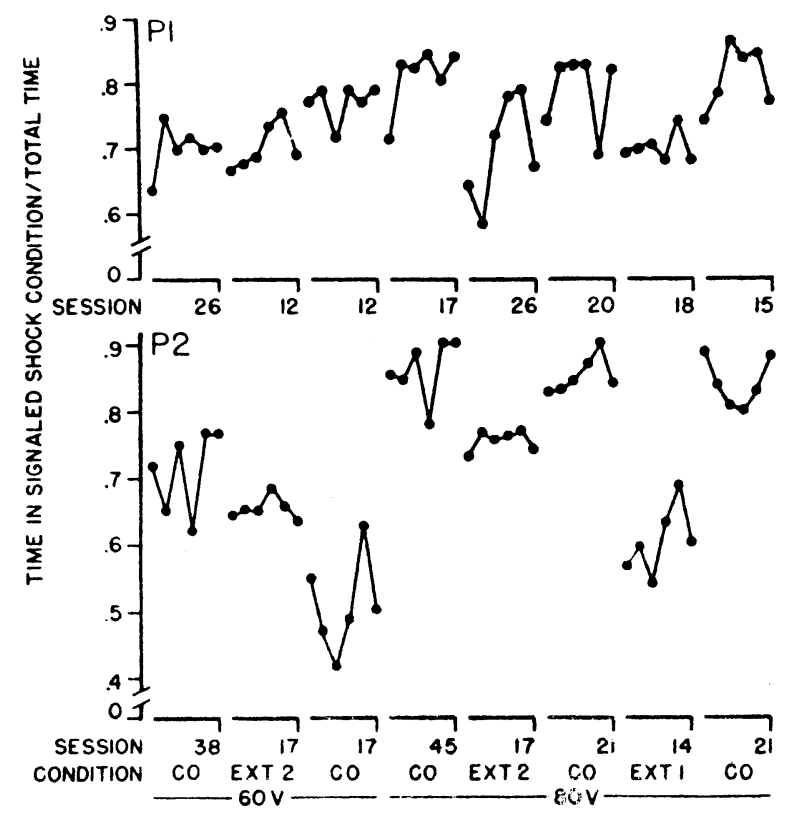

Fig. 1. Proportion of total session time spent in the signaled shock component over the final six sessions of each condition for Pigeons P1 and P2. signaled shock time between successive conditions. The EXT 1 and EXT 2 conditions differentially affected performance only for SP2, with EXT 1 resulting in more pronounced diminution of preference.

Even under the extinction conditions, the proportion of session time in the signaled shock component ranged from 0.55 to 0.78 . Since shock delivery typically resulted in movement and response bursts, it seemed likely that some portion of session time during these conditions as well as during $\mathrm{CO}$ was attributable to such responses.

An estimate of the expected time in the signaled shock component, if each shock generated a response and all changeovers were so produced, was obtained in the following manner. First, the session was divided into segments composed of the average intershock interval (expected unsignaled shock component time) plus 3.0 min (signaled shock component time). Secondly, the 3.0-min signaled shock component times were summed across all segments yielding an estimate of the total signaled shock component time. Finally, this quantity was divided by the total session time to give the expected proportion of time spent in the signaled shock component.

Figure 2 presents the differences between these estimates and the obtained values averaged over the final six sessions of each condition. This correction eliminated a substantial amount of signaled shock time, but the $\mathrm{CO}$

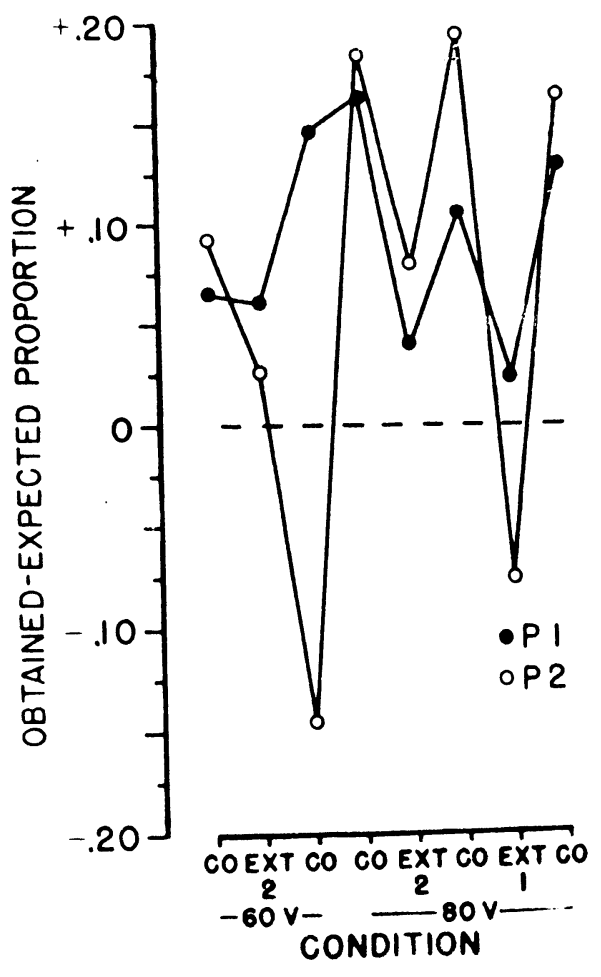

Fig. 2. Difference between obtained proportion of session time spent in the signaled shock component and the proportion of time expected due to shock-engendered responses for Pigeons $P 1$ and $P 2$. Each point represents the mean over the final six sessions of each condition. 
conditions with $80-\mathrm{V}$ shock were still associated with positive values. However, the EXT 2 conditions also maintained positive values in both Ss, indicating that shock aftereffects did not completely account for the preference under this procedure. The correction more nearly handled the preference during EXT 1, although S P1 still exhibited a slight positive value.

\section{DISCUSSION}

The pigeons in the present experiment spent more session time in the signaled shock component during $\mathrm{CO}$ than during either EXT 1 or EXT 2. These results are consistent with the Badia and Culbertson (1972) data with rats and provide extension to one member of class $A v e s$.

Badia and Culbertson (1972; see also Badia, Coker, \& Harsh, 1973; Badia, Culbertson, \& Harsh, 1973) suggested that the preshock signal segments the signaled shock component into short shock periods and relatively long safe or shock-free periods. In contrast, the entire unsignaled shock component is a shock period. It was suggested that preference for signaled shock depends upon the relatively longer shock-free periods or relatively shorter shock periods occasioned by the signaled shock component.

Dinsmoor et al (1969) trained pigeons on an appetitive, two-component mixed schedule in which responses were punished in one component. The emission of a keypeck observing response produced discriminative stimuli that identified the component in effect. The observing response was maintained if (a) it produced the discriminative stimuli for both the punishment and no-punishment components, and (b) it only produced the discriminative stimulus for the no-punishment component. If the observing response produced only the discriminative stimulus for the punishment component, responding was not maintained. Badia and Culbertson (1972) suggested that these data were congruent with their analysis, since the important determinant appeared to be delineation of shock-free time. The present data which indicate that pigeons also prefer signaled shock in the Badia and Culbertson (1972) procedure strengthen this notion.

The foregoing analysis is in contrast to the proposal that signaled shock is preferred simply because it allows $\mathrm{S}$ to alter the shock intensity by some preparatory movement or postural adjustment (Biederman \& Furedy, 1970, 1973; Furedy \& Biederman, 1972). The use of implanted electrodes appears to blunt this interpretation of the present data.

Biederman and Furedy (1973) have argued that the Badia and Culbertson (1972) results are due to photic reinforcement, i.e., due to the increase in illumination (correlated stimulus) produced by the changeover response. However, the present data are not easily interpretable via this mechanism, since both signaled and unsignaled shock components were associated with illumination. The decrement in signaled shock time during EXT 2 is also inconsistent. Although the somewhat greater signaled shock time during EXT 2 relative to EXT 1 in Pigeon P2 may indicate preference for the response-contingent light color change, the preshock signal was an additional factor as indicated by comparison of CO and EXT 2 conditions.
Biederman and Furedy (e.g., 1973), however, have presented substantial data suggesting that preference for signaled shock can be explained by either postural adjustment or photic reinforcement. It is noteworthy that, among the differences in design and analysis, their procedure involved rather short-term preference tests. It may be that the present effect as well as that of Badia and Culbertson (1972) requires more time to develop than either of the alternative mechanisms. Indeed, stability during $\mathrm{CO}$ required more than $60 \mathrm{~h}$ in some cases in the present experiment.

The time required for stability, the variability within conditions, and the diminished preference for signaled shock during $\mathrm{CO}$ relative to prior experiments with this methodology, however, suggest that the preshock signal did not maximally control preference in the present experiment. The extent to which the use of implanted electrodes damped such control can, of course, not be determined from these data. On the other hand, shock itself exerted substantial control via postshock responding. In view of the latter effect, procedures that gate out postshock responses (Badia \& Culbertson, 1972), use symmetrical changeovers (Biederman \& Furedy, 1973), or focus upon schedule effects may provide more sensitive indices for delineating additional sources of control.

\section{REFERENCES}

Azrin, N. H. A technique for delivering shock to pigeons. Journal of the Experimental Analysis of Behavior, 1959, 2, 161-163.

Badia, P., Coker, C., \& Harsh, J. Choice of higher density signalled shock over lower density unsignalled shock. Journal of the Experim ental A nalysis of Behavior, 1973, 20, 47-55.

Badia, P., \& Culbertson, S. The relative aversiveness of signalled vs unsignalled escapable and inescapable shock. Journal of the Experimental Analysis of Behavior, 1972, 17, 463-471.

Badia, P., Culbertson, S., \& Harsh, J. Choice of longer or stronger signalled shock over shorter or weaker unsignalled shock. Journal of the Experimental Analysis of Behavior, $1973,19,25-32$.

Biederman, G. B., \& Furedy, J. J. The preference-for-signalled-shock phenomenon: Signalling shock is reinforcing only if shock is modifiable. Quarterly Journal of Experimental Psychology, 1970, 22, 681-685.

Biederman, G. B., \& Furedy, J. J. Preference-for-signalled-shock phenomenon: Effects of shock modifiability and light reinforcement. Journal of Experimental Psychology, 1973, 100, 380-386.

Dinsmoor, J. A., Flint, G. A., Smith, R. F., \& Viemeister, N. F. Differential reinforcing effects of stimuli associated with the presence or absence of a schedule of punishment. In $D$. $P$. Hendry (Ed.), Conditioned reinforcement. Homewood, Ill: Dorsey Press, 1969. Pp. 357-384.

Furedy, J. J., \& Biederman, G. B. Development of the reinf orcing effect of signaling modifiable shock. Perceptual \& Motor Skills, 1972, 35, 31-34.

Knapp, R. K., Kause, R. H., \& Perkins, C. C., Jr. Immediate versus delayed shock in T-maze performance. Journal of Experimental Psychology, 1959, 58, 357-362.

Lockard, J. S. Choice of a warning signal or no warning signal in an unavoidable shock situation. Journal of Comparative \& Physiological Psychology, 1963, 56, 526-530.

Perkins, C. C., Jr., Levis, D. J., \& Seymann, R. Preference for signal-shock vs shock-signal. Psychological Reports, 1963, 13, 735-738.

Perkins, C. C., Jr., Seymann, R. G., Levis, D. J., \& Spencer, H. R., Jr. Factors affecting preference for signal-shock over shock-signal. Journal of Experimental Psychology, 1966, 72, 190-196.

(Received for publication May 20, 1974.) 